www.jmscr.igmpublication.org

Impact Factor 5.244

Index Copernicus Value: 83.27

ISSN (e)-2347-176x ISSN (p) 2455-0450

crossref DOI: _http://dx.doi.org/10.18535/jmscr/v4i8.95

Journal Of Medical Science And Clinical Research

\title{
A Study of Distress and Well-Being among Mothers of Children with ADHD and AUTISM in Rural, Coimbatore Tamilnadu
}

\author{
Authors \\ Mr Siva Shankar, $\mathbf{P}^{1}$ Arun Kumar. ${ }^{2}$, Manivasagam. $\mathbf{M}^{3}$, Anbu. N. Aravazhi ${ }^{4}$ \\ Department of Pediatrics \\ Karpagam Faculty of Medical Science and Research Coimbatore, Tamilnadu
}

\begin{abstract}
Number of studies has investigated about psychological distress of mothers of children with ADHD and AUTISM. Mothers of children with ADHD and AUTISM often experience greater stress and emotional demands. Mothers have to undertake too much stress than other family members because there mothers are with their children throughout the day. There can be exceptions for this, as not all mothers of children face highly stressful life situations. The aim of the study is to assess psychological distress such as stress, anxiety, depression and well being of mothers of children with ADHD and AUTISM.
\end{abstract}

\section{Sample}

The sample consists of 40 mothers (20 mothers of children with ADHD) and (20 mothers of children with AUTISM) from pediatric OPD of karpagam faculty of medical sciences and research coimbatore. And those met with the criteria for ICD - 10 criteria for the diagnosis of ADHD and AUTISM were included for the study.

\section{Tools used}

Beck, s depression inventory, Depression Anxiety Stress Scale.PGI well-being scale CCEI- Index. The mothers who of children diagnosed as ADHD and Autism need effective counseling to reduce the distress and improve their better well being.

Number of studies has investigated the psychological distress of mothers of children with autism and ADHD. Mothers of children with autism and ADHD often experience greater stress and emotional demands than do other mothers.
Mothers have to undergo much stress than other family members because they are with the suffering children through at the day. There can be exceptions as not all mothers of children face highly stressful situations. However it has been explained that children of mothers with Autism \& ADHD are at risk of stress related disorders. As these mothers are over burned by demands of care giving and other responsibilities (Pei-Chip Leyetal et, al 2013) further maternal attitudes affect the quality of life in mothers of child with Autism and ADHD. The birth of a children with psychological problem in a family can give a negative feelings which. Can be found in parents of children with Autism and ADHD at early and later periods in the life cycle. They are over protective helpless revulsions at the experience, in adequacy of rearing, anger, grief, shock, guilt, embarrassment (Ramli,et.al.2007). showed that parents and siblings of children with Autism and ADHD 
individually as well as the family as a whole faces of numerous difficulties. (Ramali, et, al.2007). They also found that parents of children With Autism and ADHD had significantly higher level of psychiatric symptoms and were more likely to meet criteria for depressive and anxiety disorders. Tendency towards Social isolation often encountered in families of children with Autism and ADHD. There may be an important Factor of anxiety. Carla A Mazepsky et, al. (2010) reported that mothers are especially influenced by the presence of children with Autism and ADHD in the families as there is increased demands and inconvenience associated with such a situation were most often met by mothers.

\section{Objective}

The objective of the study is to asses psychological distress such as stress, anxiety, depression and well being of mothers of children having Autism and ADHD. It is a children with Autism and ADHD hypothesis is that there would be significant psychological distress and experience of poor well being mothers of children with autism and ADHD. The sample consists of mothers of children with Autism \& ADHD with age range of 6 to Years and mothers of children with Autism with age range of 3 Years 6 Years mother's age ranged from 22 to 40 years of both groups. The study was conducted in the OPD department of pediatric department at karpagam faculty of medical science and research. Coimbatore. Tamilnadu. Inclusion criteria mothers of children with Autism and mothers of children with ADHD were included

The children with childhood disorders etc major cerebral palsy, hearing impaired were excluded. From the study. The sample consist of (40) 20 mothers of children with Autism. 20 were mothers of children with ADHD. The Children were assessed using the DDST Denver developmental screening test \& BKT Binet kamat test of intelligence to know the developmental \& intellectual level of functioning. Cars - Child hood autism rating scale \& ADHD rating scale were used to assess the severity of the criteria of ICD 10 Autism and ADHD

\section{Tools Used}

Socio demographic sheet: Socio demographic sheet was prepared for this study to collect relevant background information.

Beck Depression Inventory: (BDI) to assess depression.

Depression, Anxiety, Stress Scale (DASS): DASS is that a set of 3 Self report scales designed to measure the severity of the symptoms of depression, anxiety and stress.

PGI - Well being scale: this scale is designed to measure the well being of the individual. CCE Index: This questionnaire is used to evaluate the presence of anxiety, phobia, obsession, somatic, anxiety, depression, and hysteria. Student $t$ test is used for to know the significant differences.

\section{Results}

\begin{tabular}{|c|c|c|c|c|c|c|}
\hline SCALE & GROUP & $\mathrm{N}$ & MEAN & S.D & T VALUE & LEVEL OF SIGN \\
\hline BECK Depression & AUTISM & 20 & 34.8 & 5.85 & $9.71^{* * *}$ & $P<0.01$ \\
\hline DASS - Depression scale & $\begin{array}{c}\text { AUTISM } \\
\text { ADHD }\end{array}$ & $\begin{array}{l}20 \\
20\end{array}$ & $\begin{array}{l}10.8 \\
12.3\end{array}$ & $\begin{array}{c}1.44 \\
0.447\end{array}$ & $3.06^{* *}$ & $P<0.01$ \\
\hline DASS - Anxiety Scale & $\begin{array}{l}\text { AUTISM } \\
\text { ADHD }\end{array}$ & $\begin{array}{l}20 \\
20\end{array}$ & $\begin{array}{l}15.9 \\
15.1\end{array}$ & $\begin{array}{c}0.686 \\
1.10\end{array}$ & $3.06^{* *}$ & $P<0.01$ \\
\hline DASS - Stress scale & $\begin{array}{l}\text { AUTISM } \\
\text { ADHD }\end{array}$ & $\begin{array}{l}20 \\
20\end{array}$ & $\begin{array}{l}15.9 \\
15.1\end{array}$ & $\begin{array}{c}0.686 \\
1.10\end{array}$ & $3.11^{* *}$ & NS \\
\hline CCEI-Anxiety & $\begin{array}{c}\text { AUTISM } \\
\text { ADHD }\end{array}$ & $\begin{array}{l}20 \\
20\end{array}$ & $\begin{array}{l}14.9 \\
13.6\end{array}$ & $\begin{array}{c}0.999 \\
1.19\end{array}$ & $3.89^{* *}$ & $P<0.01$ \\
\hline CCEI - Phobia & $\begin{array}{l}\text { AUTISM } \\
\text { ADHD }\end{array}$ & $\begin{array}{l}20 \\
20\end{array}$ & $\begin{array}{l}6.70 \\
6.20\end{array}$ & $\begin{array}{l}1.56 \\
1.47\end{array}$ & 1.04 & NS \\
\hline CCEI-Obsession & $\begin{array}{c}\text { AUTISM } \\
\text { ADHD }\end{array}$ & $\begin{array}{l}20 \\
20\end{array}$ & $\begin{array}{l}6.20 \\
6.15\end{array}$ & $\begin{array}{c}1.74 \\
0.988\end{array}$ & 0.112 & NS \\
\hline CCEI - Depression & $\begin{array}{l}\text { AUTISM } \\
\text { ADHD }\end{array}$ & $\begin{array}{l}20 \\
20 \\
\end{array}$ & $\begin{array}{l}8.10 \\
12.4\end{array}$ & $\begin{array}{l}1.55 \\
1.32 \\
\end{array}$ & $9.56^{* *}$ & $P<0.01$ \\
\hline CCEI - Somatic anxiety & $\begin{array}{c}\text { AUTISM } \\
\text { ADHD }\end{array}$ & $\begin{array}{l}20 \\
20\end{array}$ & $\begin{array}{l}6.40 \\
6.35\end{array}$ & $\begin{array}{l}1.05 \\
1.09\end{array}$ & 1.63 & NS \\
\hline CCEI - Hysteria & $\begin{array}{c}\text { AUTISM } \\
\text { ADHD }\end{array}$ & $\begin{array}{l}20 \\
20\end{array}$ & $\begin{array}{l}6.30 \\
6.35\end{array}$ & $\begin{array}{l}1.34 \\
1.84 \\
\end{array}$ & 0.981 & NS \\
\hline PGI-Well being scale & $\begin{array}{l}\text { AUTISM } \\
\text { ADHD }\end{array}$ & $\begin{array}{l}20 \\
20\end{array}$ & $\begin{array}{l}15.9 \\
14.4\end{array}$ & $\begin{array}{l}0.945 \\
1.27\end{array}$ & $4.37^{* * *}$ & $P<0.01$ \\
\hline
\end{tabular}

\section{Discussion}

The $t$ test used to determine the significance of differences between means scores of depression and anxiety and well - being of mothers of children. With Autism \& ADAD mean age of child with is Autism is (3.95) and ADHD is (8.25). The mean age of mother, of Autism is (25.95) SD is (2.523) mean age of ADHD is (31.85) SD is (2.523) mean age of ADHD is SD is (3.345).The scores of BDI of Mothers of Autism and ADHD shows significant differences between 
the groups ( $\mathrm{P}$ is <0.01) Where Mothers of ADHD who Children scored higher than Autism. The BDI Scores studies found (Harrison and fofronoff, 2002) found that mothers of ADHD children have significant negative emotional depressive symptoms in Mothers (Ramall bin musa, et, al. 2007) studies of mothers of children with suggest that $63 \%$ of mothers with children with ADHD have depression. The sub scale of DASS depressive mothers of children with ADHD and AUTISM were compared. There is significance differences between the groups ( $\mathrm{P}$ is $<0.01$ ) where mothers of children with Autism and ADHD scored higher then children mean found higher depression in mothers of children with ADHD. (Mashes, et, al. of 1983) found mothers of children with ADHD high depression scores. The sub scale of DASS Anxiety scales of mothers of children with Autism and ADHD children were compared.

There is significance differences between the groups ( $\mathrm{P}$ is $<0.01$ ) where mothers of AUTISM children scored higher the mothers of children with ADHD. Studies have found (Baviar DB,et,al.1995) found anxiety was significantly higher among the mothers of children with AUTISM (Bolton Pf, et, al.) study reported that mothers of children with Autism have higher anxiety and depression. On the sub scales of DASS, stress scale, there is no significant differences between two groups namely mothers of children Autism and ADHD children.

The sub scale of CCEI Anxiety of mothers of children with Autism ADHD were compared. There is significance differences between the groups ( $\mathrm{P}$ is $<0.01$ ) where mothers of children Autism with scored higher than ADHD children. Some studies have found anxiety and depression were significantly higher among mothers of AUTISM children. (Ghaziuddin,et,al.1998) found depression and higher level of anxiety in mothers of children with Autism. The sub scale of CCEI Phobia and obsession somatic anxiety and Hysteric there is no significant differences between mothers children with Autism and children with ADHD. The sub scale of CCEI Depression mothers of children with Autism and ADHD children were compared. There is significance differences between the groups ( $\mathrm{P}$ is $<0.01)$ where mothers of ADHD children scored higher. (Carla A Mazefskys, et, al.2010) investigating the mental health of parents with children with AUTISM and ADHD have found higher scores for maternal depression compared to norms of children with Autism \& ADHD are at an high risk of depression, while their spouse were not?

In PGI - Well - being scale there is significant differences between mothers of Autism and ADHD. There is significant differences between the groups ( $\mathrm{P}$ is $<0.01$ ) where mothers of Autism ADHD children scored higher. Formed that mothers with Autism and ADHD children have higher anxiety, depression affect negatively well being of mothers.

(Mohammed A, et, al.2013) indicated that mothers of children with Autism \& ADHD had decreased well being. Well-being level decreased while child grow up significant.

Conclusion

The findings of this study indicated that mothers of children with Autism and ADHD have depression and anxiety. Increased depression and anxiety level affected the well being of there mothers. The Child with Autism and ADHD need effective rehabilitation training programme and mothers need counseling and effective psychological support to manage distress and have a better well-being.

\section{References}

1. Carla A. Mazefsky, Caitlin M conner, and Donald p. Oswald (2010) Association between depression and anxiety In high functioning in children with autism spectrum disorders and an maternal a mood symptoms. Autism research journal : 3 (3): $120-127$

2. Harrision, C., Sofrronoff. K. (2002) ADHD and parental psychological 
distress: role of demographics, child behavioural characteristics, and parental cognitions. Journal of American Academy Child and Adolescent psychiatry; 4:703-11

3. Mash, EJ, Johnson, C, (1998) Siblings Interactions of hyperactive and normal children and their relationships to reports maternal stress and esteem. Journal of clinical psychology ; 12: 91-9.

4. Pie- Chinlee, ken - Chunglin, Deebran, Robson, Hao-jan yang, Vincent- chin Hung chen, Wern- ing niew (2013) parent child interactions of mothers with depression and their child with ADHD. Journal of Developmental Disabilities , volume $34^{\text {th }}$ issue.

5. Ravalli bin Musa and Zasmani Shafiee (2007) Depression , anxiety and stress levels among mothers of ADHD children and their relationships to ADHD symptoms. Asean Journal of psychiatry 8 (1): 20-28. 